\title{
DcpS is a transcript-specific modulator of RNA in mammalian cells
}

\author{
MI ZHOU, ${ }^{1}$ SOPHIE BAIL, ${ }^{1}$ HEATHER L. PLASTERER, ${ }^{2}$ JAMES RUSCHE, $^{2}$ and MEGERDITCH KILEDJIAN ${ }^{1}$ \\ ${ }^{1}$ Department of Cell Biology and Neuroscience, Rutgers University, Piscataway, New Jersey 08854, USA \\ ${ }^{2}$ Repligen Corporation, Waltham, Massachusetts 02453, USA
}

\begin{abstract}
The scavenger decapping enzyme DcpS is a multifunctional protein initially identified by its property to hydrolyze the resulting cap structure following $3^{\prime}$ end mRNA decay. In Saccharomyces cerevisiae, the DcpS homolog Dcs 1 is an obligate cofactor for the $5^{\prime}-3^{\prime}$ exoribonuclease Xrn1 while the Caenorhabditis elegans homolog Dcs-1, facilitates Xrn1 mediated microRNA turnover. In both cases, this function is independent of the decapping activity. Whether DcpS and its decapping activity can affect mRNA steady state or stability in mammalian cells remains unknown. We sought to determine DcpS target genes in mammalian cells using a cell-permeable DcpS inhibitor compound, RG3039 initially developed for therapeutic treatment of spinal muscular atrophy. Global mRNA levels were examined following DcpS decapping inhibition with RG3039. The steady-state levels of 222 RNAs were altered upon RG3039 treatment. Of a subset selected for validation, two transcripts that appear to be long noncoding RNAs HS370762 and BC011766, were dependent on DcpS and its scavenger decapping catalytic activity and referred to as DcpS-responsive noncoding transcripts (DRNT) 1 and 2, respectively. Interestingly, only the increase in DRNT1 transcript was accompanied with an increase of its RNA stability and this increase was dependent on both DcpS and Xrn1. Importantly, unlike in yeast where the DcpS homolog is an obligate cofactor for Xrn1, stability of additional Xrn1 dependent RNAs were not altered by a reduction in DcpS levels. Collectively, our data demonstrate that DcpS in conjunction with Xrn1 has the potential to regulate RNA stability in a transcript-selective manner in mammalian cells.
\end{abstract}

Keywords: RNA decay; DcpS; XRN1; IncRNA

\section{INTRODUCTION}

In eukaryotic cells, mRNA degradation plays an important role in the control of gene expression and therefore is highly regulated. Following an initial deadenylation step to remove the $\operatorname{poly}(\mathrm{A})$ tail, the remaining mRNA can undergo exonucleolytic decay from either $3^{\prime}$ or the $5^{\prime}$ end. In the $5^{\prime}$ to $3^{\prime}$ decay pathway, the $5^{\prime}$ cap is initially removed by Dcp 2 or Nudt 16 decapping enzymes, resulting in a $5^{\prime}$ end monophosphorylated RNA (Lykke-Andersen 2002; van Dijk et al. 2002; Wang et al. 2002; Song et al. 2010). The uncapped product undergoes $5^{\prime}$ to $3^{\prime}$ exoribonuclease decay by, Xrn1 (Hsu and Stevens 1993). Xrn1 is highly conserved in eukaryotes and functions in the decay of cytoplasmic mRNAs (Muhlrad et al. 1995), in the quality control of aberrant mRNAs (Conti and Izaurralde 2005) and noncoding RNAs (Chernyakov et al. 2008; van Dijk et al. 2011). In the $3^{\prime}$ to $5^{\prime}$ pathway, the multisubunit exosome complex degrades the deadenylated RNA from the $3^{\prime}$ end, leaving the residual $\mathrm{m}^{7} \mathrm{GpppN}$ cap structure (Anderson and Parker 1998; Liu et al. 2006). The resulting cap structure is a substrate of the scavenger decapping

Corresponding author: kiledjian@biology.rutgers.edu

Article published online ahead of print. Article and publication date are at http://www.rnajournal.org/cgi/doi/10.1261/rna.051573.115. enzyme, DcpS to release $\mathrm{m}^{7} \mathrm{Gp}$ and ppN products (Wang and Kiledjian 2001; Liu et al. 2002). In yeast, the DcpS homolog Dcs1p, facilitates $5^{\prime}$ to $3^{\prime}$ exoribonucleolytic decay (Liu and Kiledjian 2005) as an obligate cofactor for the Xrn1 exoribonuclease by an unknown mechanism independent of its decapping catalytic activity (Sinturel et al. 2012). Moreover, the Caenorhabditis elegans Dcs-1 was shown to physically interact with Xrn-1 and promote specific microRNA degradation also independent of its decapping activity (Bosse et al. 2013).

DcpS hydrolyzes the triphosphate linkage of the cap structure utilizing an evolutionarily conserved Histidine Triad (HIT) motif (Liu et al. 2002) with the central histidine serving as the nucleophile for the hydrolase activity (Lima et al. 1997). Insights into the molecular mechanism of DcpS decapping were provided by structural analysis, revealing a homo-dimer complex where each monomer possesses a distinct binding and active site ( $\mathrm{Gu}$ et al. 2004). The homodimer displays an asymmetric structure in the ligand-bound

(c) 2015 Zhou et al. This article is distributed exclusively by the RNA Society for the first 12 months after the full-issue publication date (see http:// rnajournal.cshlp.org/site/misc/terms.xhtml). After 12 months, it is available under a Creative Commons License (Attribution-NonCommercial 4.0 International), as described at http://creativecommons.org/licenses/by-nc/4.0/. 
form and a dynamic state, where each monomer can alternate from an open to closed state (Liu et al. 2008). Hydrolysis of cap structure only occurs in the closed conformation $(\mathrm{Gu}$ et al. 2004).

A potent DcpS decapping inhibitor was identified in efforts to isolate small molecules that increase expression of the survival of motor neuron 2 (SMN2) gene in spinal muscular atrophy (SMA) patients. Cocrystal structures of a C5 substituted quinazoline compound, D156844, revealed it binds to the DcpS cap binding active site and inhibits its decapping (Singh et al. 2008; Thurmond et al. 2008). Further optimization generated the RG3039 derivative, which is also a potent DcpS decapping inhibitor (Gogliotti et al. 2013). Although the quinazoline compounds were capable of improving motor neuron function and extending survival of SMA model mice (Butchbach et al. 2010; Gogliotti et al. 2013; Van Meerbeke et al. 2013), statistically significant increases in SMN2 mRNA or SMN protein were not evident. In this study, we took advantage of the DcpS decapping inhibition property of RG3039 to determine the impact of DcpS decapping on mRNA expression. Interestingly, only 222 RNAs were detected to be altered upon RG3039 treatment and of a subset of genes validated, four were found to be responsive to RG3039 independent of DcpS and two were mediated through DcpS. Importantly, both the DcpS-responsive transcripts are putative noncoding RNAs, with the stability of one RNA modulated by both DcpS and Xrn1. Our data indicate that DcpS has the capacity to be a transcript-restricted modulator of RNA stability in mammalian cells and the RG3039 quinazoline compound is more pleotropic than initially anticipated and can influence gene expression in both an apparent DcpS dependent and independent manner.

\section{RESULTS}

\section{Steady-state levels of RNAs are altered in cells treated with RG3039}

Despite its role in the last step of $3^{\prime}$ end mRNA decay pathway, DcpS also contributes to mRNA or miRNA turnover in S. cerevisiae and C. elegans, respectively. To determine whether the human DcpS decapping activity influences the expression of mRNAs in mammalian cells, we took advantage of a small molecule inhibitor of DcpS decapping, RG3039, to monitor changes in global mRNA levels. RG3039 is a cell-permeable quinazoline derivative that is a potent inhibitor of DcpS decapping (Singh et al. 2008; Gogliotti et al. 2013) and was used to inhibit cellular DcpS activity and monitor potential changes in RNA steady-state levels. RNA isolated from human SH-SY5Y retinoblastoma cells treated for $2 \mathrm{~d}$ with $100 \mathrm{nM}$ RG3039 were analyzed on an Affymetrix U133 Plus 2.0 human microarray. RNA profiles from treated and untreated cells revealed levels of 222 RNA were altered more than twofold between the two cell parameters with $P$ values $<0.05$ (Supplemental Table S1) with 171 increased and 51 de- creased. Approximately 75\% of the RNAs corresponded to mRNAs, while $\sim 25 \%$ mapped to uncharacterized transcripts consistent with noncoding RNA. A subset of 12 RNAs were randomly chosen for further validation by direct quantitative reverse-transcription (qRT)-PCR. The steady-state levels of six were found to reproducibly and significantly change greater than twofold upon RG3039 treatment. The levels of four RNAs, HS370762, BC011766, ATOH7, and RAB26, were elevated, while PAQR8 and MAOB were reduced compared with untreated cells (Fig. 1A). Similar changes for the six RNAs were also detected in HEK293T cells treated with $100 \mathrm{nM}$ RG3039 (Fig. 1B) demonstrating the generality of the results in different cell lines. All subsequent analyses were carried out in HEK293T cells.

\section{RNA steady-state levels are influenced by DcpS}

To determine whether the changes in the levels of the six RNAs were mediated through DcpS, we utilized a HEK293T cell line constitutively expressing a DcpS-directed shRNA (DcpS ${ }^{\mathrm{KD}}$ ) which reduced DcpS protein levels by $90 \%$ (Fig. 2A; Shen et al. 2008). Consistent with the outcome of RG3039 treated cells, steady-state levels of both HS370762

\section{A}

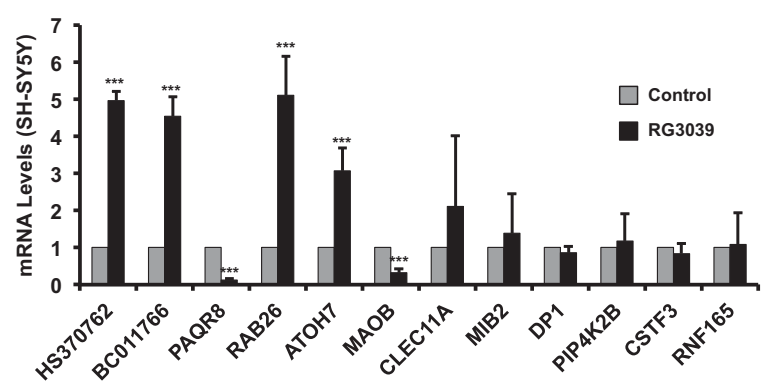

B

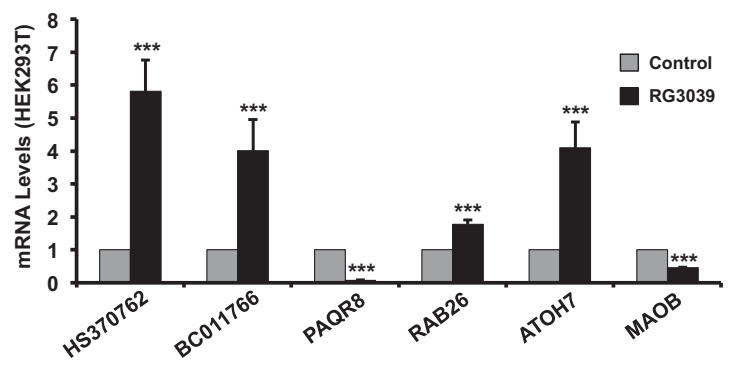

FIGURE 1. Validation of a subset of RG3039 target RNAs. (A) Levels of 12 randomly chosen RNAs from the 222 RNAs that deviated by at least twofold in SH-SY5Y neuroblastoma cells treated for $48 \mathrm{~h}$ with $100 \mathrm{nM}$ RG3039 were tested by quantitative reverse-transcription (qRT)-PCR. RNA levels are presented relative to actin mRNA and derived from at least three independent experiments. Six of the RNAs were reproducibly altered greater than twofold and constitute RG3039 responsive RNAs. (B) Validated RG3039 target RNAs from SH-SY5Y cells were further confirmed in HEK293T cells to determine the consistency of RG3039 in different cell backgrounds. RNA levels are presented relative to the GAPDH mRNA and derived from at least three independent experiments. All six RNAs were similarly altered in the HEK293T cells as they were in SH-SY5Y cells. Error bars represent \pm SD. $\left({ }^{* * *}\right) P<0.001$ (Student's $t$-test). 
A
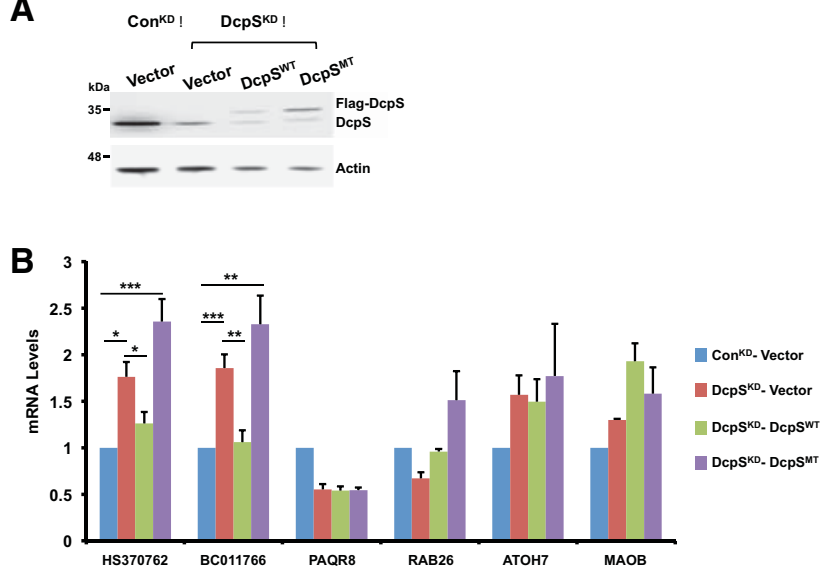

FIGURE 2. RG3039 target RNAs, HS370762, and BC011766 are regulated by DcpS. (A) Endogenous and exogenously expressed DcpS protein levels were measured by Western blot in HEK293T control knock down $\left(\mathrm{Con}^{\mathrm{KD}}\right)$ or DcpS knock down $\left(\mathrm{DcpS}^{\mathrm{KD}}\right)$ cells, complemented with shRNA-resistant DcpS ${ }^{\text {WT }}$ of a catalytically inactive DcpS harboring a histidine 277 to asparagine $\left(\mathrm{DcpS}^{\mathrm{MT}}\right)$ mutation as shown. Complementation with a control plasmid lacking the DcpS cDNA is denoted as "Vector." ( $B)$ RNA levels for the indicated RNAs were measured by qRT-PCR from cells in A. RNA levels are presented relative to the GAPDH mRNA and derived from three independent experiments. RNA levels for only HS370762 and BC011766 were responsive to depletion and complementation with DcpS. Error bars represent \pm SD. $P$ values are denoted by asterisks; $\left(^{*}\right) P<0.05,\left({ }^{*}\right) P<0.01,\left({ }^{* * *}\right)$ $P<0.001$ (Student's $t$-test).

and BC011766 increased in DcpS ${ }^{\mathrm{KD}}$ cells (Fig. 2B). Complementation with shRNA-resistant exogenous wild-type DcpS $\left(\mathrm{DcpS}^{\mathrm{WT}}\right)$ (Fig. $\left.2 \mathrm{~A}\right)$, but not a catalytically inactive DcpS mutant (Fig. 2A) harboring an asparagine in the central histidine of the HIT motif $\left(\mathrm{DcpS}^{\mathrm{MT}}\right)$, reversed the phenotype and reduced their RNA to levels comparable with control cells (Fig. 2B). These data demonstrate that steady-state accumulation of HS370762 and BC011766 RNAs are modulated by DcpS and moreover, by the decapping activity of DcpS. In contrast, levels of the remaining four mRNAs were either consistent with RG3039 treatment but not complemented by DcpS, or inconsistent with RG3039 treatment suggesting they are not direct DcpS targets. We conclude DcpS decapping activity is important in HS370762 and BC011766 RNA expression, while the levels of ATOH7, RAB26, PAQR8, and MAOB mRNAs are responsive to RG3039 in a DcpS-independent manner.

\section{HS370762 and BC011766 transcripts are putative noncoding RNAs}

HS370762 and BC011766 are uncharacterized transcripts. HS370762 maps to human EST AW665080 on a region of chromosome 9 containing multiple ESTs (Fig. 3A) and BC011766 maps to a short transcript on human chromosome 3 (Fig. 3D). Rapid amplification of cDNA ends (RACE) analysis was used to map the termini of both RNAs. The $3^{\prime}$ poly- adenylated tail of HS370762 was identified with oligo(dT) linked adaptor $3^{\prime}$ race and found to correspond to the minus strand. 5' RACE extended the RNA to the $5^{\prime}$ end of the AW665080 EST. Multiple ESTs contiguous with the DNA map to this region indicating HS370762 is a nonspliced transcript. The $5^{\prime}$ end was further confirmed by direct reverse transcription and PCR (RT-PCR) amplification with a series of 5' primers within, and upstream of, AW665080. As expected, a robust RT-PCR product resulted with the AW665080 specific primers, while primers upstream of AW665080 generated relatively less intense products (Fig. 3B) suggesting the predominant transcript corresponded to the AW665080 EST. More significantly, qRT-PCR analysis confirmed RNA from AW665080 was responsive to RG3039 treatment, while transcripts transcribed from regions upstream of this EST were not responsive to RG3039 (Fig. 3C). The lack of an extensive open reading frame within this 490 nt RNA suggests HS370762 is likely a noncoding RNA that we will refer to as DcpS-responsive noncoding transcript 1 (DRNT1).

A similar analysis was carried out to map the BC011766 RNA. The $3^{\prime}$ polyadenylated tail of BC011766 was identified and corresponded to the minus strand. 5' RACE of BC011766 revealed the major transcript of $\sim 500 \mathrm{nt}$ contiguous with the genomic sequence (Fig. 3D,E). Unexpectedly the 5' RACE also revealed a less intense and longer product that extended an additional $1100 \mathrm{nt}$ contiguous with the genomic sequence upstream of the $5^{\prime}$ end of BC011766. To verify whether this longer transcript was an isoform of $\mathrm{BC} 011766$, qRT-PCR primers that amplified a region 150 bp upstream of BC011766 confirmed the low abundance of this transcript and its lack of response to RG3039 treatment (Fig. 3F), indicating that only levels of the 518-nt BC011766 RNA are elevated by an inhibition of DcpS decapping. The lack of a predicted open reading frame in the $\mathrm{BC} 011766 \mathrm{RNA}$ indicates it is also a noncoding RNA we will refer to as DcpS-responsive noncoding transcript 2 (DRNT2).

\section{DRNT1 RNA stability is altered by RG3039}

We next determined whether changes in the steady-state levels of the RG3039 target RNAs could be attributed to transcript stability. RNA half-lives for the six different RG3039 targets were determined following actinomycin D-directed transcriptional silencing in RG3039 treated or untreated HEK293T cells. Consistent with the observed increase in DRNT1 steady-state levels, its stability increased twofold with RG3039 treatment (Fig. 4) while the stability of DRNT2 was unchanged following RG3039 treatment. Interestingly, the PAQR8 mRNA was destabilized by RG3039 treatment. This result is consistent with the observed RG3039mediated decrease in PAQR8 mRNA steady-state levels (Fig. 2). Stability of the remaining mRNAs was refractory to RG3039 treatment indicating the changes in steady-state mRNA levels for these mRNAs were not mediated through transcript stability. Collectively, our data reveal that RG3039 


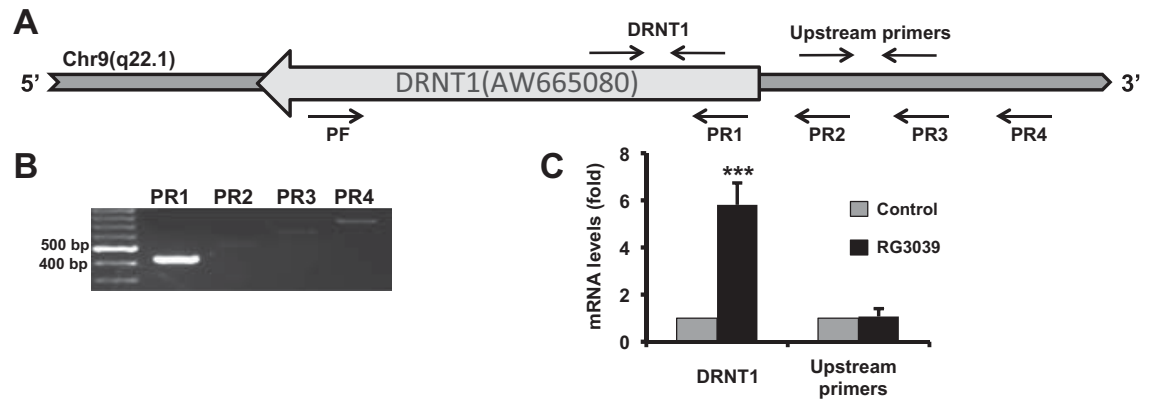

D

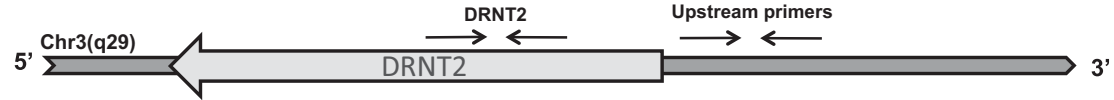

E

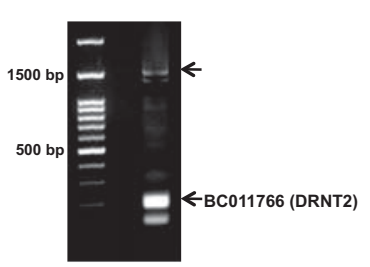

$\mathbf{F}$

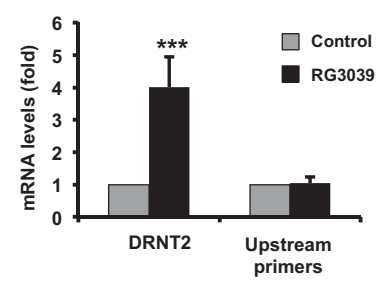

FIGURE 3. Mapping the genomic loci corresponding to HS370762 (DRNT1) and BC011766 (DRNT2) RNAs. (A) Schematic of the genomic loci and direction on Chromosome 9 for HS370762/DRNT1 is shown. Black arrows indicate position and orientation of primers used in B,C. (B) PCR of oligo(dT) reverse transcribed total RNA from HEK293T cells using the PF forward primer and the four different reverse primers (PR1, PR2, PR3, and PR4) are shown. $(C)$ Levels of HS370762/DRNT1 RNA and potential transcript originating upstream of HS370762 quantitated by qRT-PCR from RNA derived from RG3039 treated or untreated HEK293T cells. (D) Schematic of the BC011766/DRNT2 genomic loci on chromosome 3. Black arrows indicate positions of qRT-PCR primers used in F. (E) Agarose gel of 5'RACE products. (F) Quantitation of DRNT2 and potential longer isoform of BC011766 (DRNT2) RNAs are presented relative to GAPDH mRNA and derived from three independent experiments.

ponent of the $3^{\prime}-5^{\prime}$ exosome complex, stabilized DRNT1 (Fig. 5B), indicating that DRNT1 is primarily degraded by Xrn 1 in the $5^{\prime}$ end decay pathway. Importantly, the stability of DRNT1 was comparable in cells with either singular reduction of DcpS or Xrn1 proteins (Fig. 5B) or both reduced simultaneously (Fig. 5C,D) suggesting DcpS functions in the same pathway as, and likely with, Xrn1. In contrast, PAQR8 and DRNT2 RNAs were both stabilized with reduced Xrn1 levels but not DcpS (Fig. 5B). These data demonstrate DcpS and Xrn1 do not coordinately regulate all Xrn1 responsive RNAs and the observed coordinate regulation of DRNT1 by DcpS and Xrn1 is transcript specific and dependent on DcpS catalytic activity.

\section{DISCUSSION}

In this study, we demonstrate that the human DcpS protein and the DcpS decapping inhibitor, RG3039, both confer regulatory roles on gene expression. Accumulation of a small subset of RNAs changed upon treatment of either SH-SY5Y or HEK293T cells with RG3039. Of the six validated, increases in DRNT1 and DRNT2 were mediated is pleotropic and has the capacity to impart transcript-specific regulation of a subset of RNAs either through RNA stability (DRNT1 and PAQR8) or by a manner independent of RNA stability (DRNT2, ATOH7, RAB26, and MAOB).

\section{DcpS modulates the stability of DRNT1}

DRNT1 RNA stability was next examined in $\mathrm{DcpS}^{\mathrm{KD}}$ cells (Fig. 5A) to determine whether the RG3039-directed increase in DRNT1 stability was mediated through DcpS. The half-life of DRNT1 increased in $\mathrm{DcpS}^{\mathrm{KD}}$ cells relative to control cells ( $T_{1 / 2}$ of 2.7 and $1.7 \mathrm{~h}$, respectively), while statistically significant changes in half-lives were not observed for PAQR8 and DRNT2 RNAs (Fig. 5B). Furthermore, lentiviral-directed shRNA knockdown of Xrn1 but not Rrp41 com-
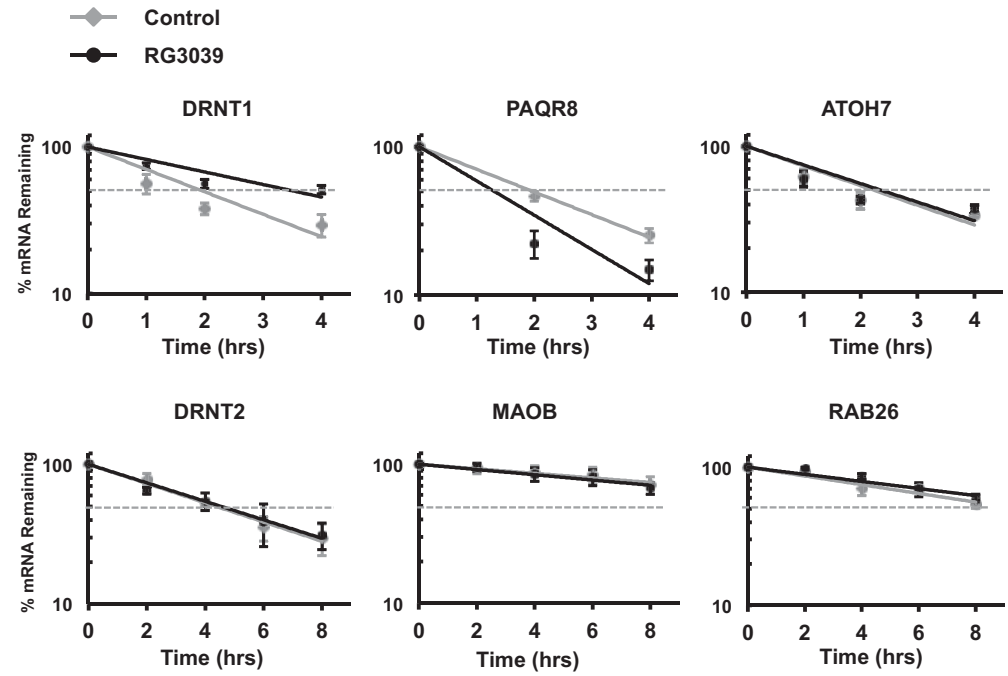

FIGURE 4. RG3039 influences the stability of HS370762 and PAQR8 RNAs. Stability of the denoted RNAs was determined following actinomycin D-mediated transcriptional silencing in HEK293T cells treated or untreated with RG3039. Values normalized to levels of GAPDH mRNA are presented relative to their respective levels at time zero. Data were derived from at least three independent experiments. Dotted line represents $50 \%$. 
A

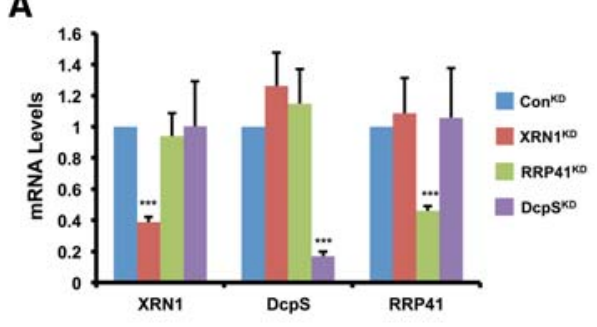

C

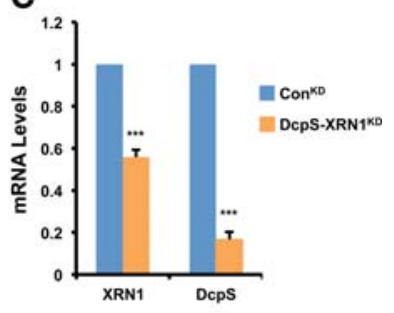

B
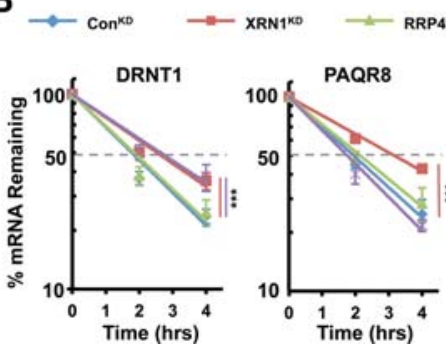

D

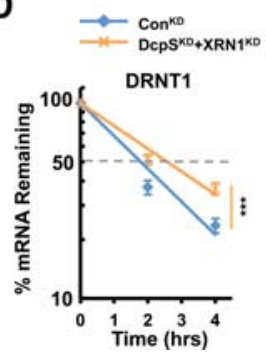

FIGURE 5. Stability of the DRNT1 RNA is mediated through both DcpS and Xrn1. (A) DcpS, XRN1, and RRP41 mRNA levels were measured by qRT-PCR in HEK293T cells with control or the indicated mRNA knock down backgrounds. (B) Degradation of the indicated RNAs was determined by qRT-PCR in cells from $A$ and as described in the legend of Figure 4. $(C)$ Levels of DcpS and XRN1 mRNAs were measured by qRT-PCR in HEK293T cells with either a control or double DcpS and XRN1 knocking down. (D) Degradation of the DRNT1 mRNA was determined by qRT-PCR in cells from $C$ and as described in the legend of Figure 4. All mRNA levels are presented relative to GAPDH mRNA and derived from three independent experiments; $P$-values from comparison of the decay rates are presented with asterisks. $\left.{ }^{* * *}\right) P<0.001$ (two-tailed extra sum-of-squares $F$ test).

through the inhibition of DcpS decapping since a similar increase was also observed in cells knocked down for DcpS that could be complemented with wild type but not a catalytically inactive DcpS protein (Fig. 2). The function of RG3039 on the remaining four mRNAs was through a mechanism independent of DcpS (Fig. 2). In the case of PAQR8, RG3039 promoted rapid decay of this mRNA while the stability of ATOH7, RAB26, and MAOB were unaffected suggesting an mRNA stability independent route. Our data further demonstrate a transcript-specific role of DcpS in RNA decay where the stability of DRNT1, but not DRNT2 was increased in $\mathrm{DcpS}^{\mathrm{KD}}$ cells indicating DcpS promotes selective decay of DRNT1. Furthermore, the comparable increase of DRNT1 stability in $\mathrm{DcpS}{ }^{\mathrm{KD}}, \mathrm{Xrn} 1^{\mathrm{KD}}$, and double $\mathrm{DcpS}^{\mathrm{KD}}$ and $\mathrm{Xrn} 1^{\mathrm{KD}}$ cells suggests both proteins function within the same pathway and DcpS likely accentuates Xrn1 function similar to that reported in S. cerevisiae (Sinturel et al. 2012) and C. elegans (Bosse et al. 2013). Interestingly, unlike the scenario in S. cerevisiae and C. elegans where the decapping activity of the DcpS homolog was dispensable for its stimulation of Xrn1 decay, human DcpS requires a functional catalytic decapping activity. Collectively, our data demonstrate the following: (1) RG3039 can modulate the expression of a subset of transcripts by DcpS dependent and independent mechanisms; (2) despite functioning in the last step of mRNA 3'end decay, human DcpS can also modulate RNA stability in a transcript-specific manner and this modulation

is dependent on its decapping activity and mediated through Xrn1.

RG3039 was initially identified and developed as a drug candidate for the treatment of SMA (Jarecki et al. 2005; Singh et al. 2008; Thurmond et al. 2008) and can increase the survival of mouse models of SMA (Butchbach et al. 2010; Gogliotti et al. 2013; Van Meerbeke et al. 2013). Despite it being a potent inhibitor of DcpS decapping (Singh et al. 2008), the lack of detectable increase in SMN mRNA and protein in treated animals confounds the mechanism by which RG3039 promotes survival of SMA mice. Our results demonstrate that RG3039 can modulate RNA levels through its inhibition of DcpS as well as a mechanism independent of DcpS. Steady-state levels of DRNT1 and DRNT2 increased with either RG3039 treatment (Fig. 1) or knock down of DcpS (Fig. 2). The complementation of this phenotype with wild type but not a catalytically inactive DcpS demonstrates the significance of DcpS decapping for this phenotype. Surprisingly, modulation of four of the characterized RG3039 target RNAs (PAQR8, ATOH7, RAB26, and MAOB) did not appear to be mediated through DcpS. Interestingly, the steady-state increase in DRNT1 and decrease in PAQR8 could be attributed to a respective increase and decrease in RNA stability, while the stability of the remaining four RNAs were refractory to RG3039 treatment. How RG3039 can modulate RNA levels through distinct mechanisms and whether its positive outcome in SMA model mouse is mediated through DcpS remain to be determined.

Of particular note, the two DcpS-responsive RNAs were both lncRNAs. Interestingly, DcpS was recently implicated in a quality control mechanism that functions to clear aberrant U1 snRNAs (Shukla and Parker 2014). However, we have been unable to detect a role for DcpS in the stability of wild-type U1 snRNA (M Zhou and M Kiledjian, unpubl.), further underscoring the transcript specificity of DcpS-mediated regulation of RNA stability.

At present, the mechanism by which DcpS confers stability is unclear, however, the stimulation of Xrn1 in humans is likely different than that observed in yeast and worms. We have been unable to detect a direct stable interaction between DcpS and Xrn1 by coimmunoprecipitations with or without crosslinking (data not shown) and unable to distinguish whether the stimulation of Xrn1 activity by DcpS is direct or indirect. The requirement of DcpS decapping activity and the lack of detectable interaction between DcpS and Xrn1 suggest a potential indirect mechanism. Whether 
accumulation of cap structure, as implicated in the efficiency of first intron splicing (Bail and Kiledjian 2008; Shen et al. 2008) or possible cap structure byproducts generated in the absence of DcpS (Taverniti and Séraphin 2014) may influence Xrn1 activity remains to be determined.

Collectively, despite its initial described function in the last step of the mRNA $3^{\prime}$ end decay pathway, DcpS is a multifunctional protein involved in a greater network of regulated gene expression. The broader significance of DcpS is further evident by the embryonic lethal phenotype in homozygous disrupted DcpS in mouse (M Kiledjian, unpubl.), and the requirement of DcpS for cell viability in CRISPR knockout screens of human genes (Shalem et al. 2014). However, it is evident that DcpS fulfills both a decapping-dependent and -independent function. The recent identification of individuals with homozygous mutations disrupting DcpS decapping activity as the underlying cause of intellectual disability (Ahmed et al. 2015; Ng et al. 2015) demonstrates the importance of DcpS decapping in normal cognition. Nevertheless, the viability of the affected individuals with DcpS decapping null mutations in contrast to the embryonic lethality of mice lacking DcpS expression demonstrates a distinct decappingindependent function for DcpS in embryogenesis and a decapping-dependent role for DcpS in normal neural function. The mechanism underlying how DcpS can modulate the stability of specific substrates and whether DRNT1 and DRNT2 contribute to human cognition awaits future analyses.

\section{MATERIALS AND METHODS}

\section{Plasmid constructs}

The pcDNA3-Flag-DcpS ${ }^{\mathrm{H} 277 \mathrm{~N}}$ plasmid was generated replacing the wild-type DcpS open reading frame from pcDNA3-Flag-DcpS (Liu et al. 2008) with the DcpS cDNA containing the H277N mutation from pET-hDcpS-H277N (Liu et al. 2002) at the Bam HI/XhoI restriction sites. The pTK-IREShyg-Flag-DcpS ${ }^{\mathrm{WT}}$ and pTK-IREShygFlag-DcpS ${ }^{\mathrm{H} 277 \mathrm{~N}}$ plasmid were constructed by inserting wild-type and mutant human DcpS open reading frames amplified from pcDNA3-Flag-DcpS and pcDNA3-Flag-DcpS ${ }^{\mathrm{H} 277 \mathrm{~N}}$ using primers 5'-CACTATAGGCTAGCATGGACTACAAGGACGACG-3' and 5' TTATCTATGCGGCCGCCAGTGTGATGGATTCAG-3' containing an NheI and NotI restriction endonuclease site respectively into the same sites of the pTK-IREShyg-Flag plasmid (Tan et al. 2014). The shRNA-resistant plasmid pTK-Flag-Dcps ${ }^{\mathrm{WT}}$ shRR and pTK-Flag-DcpS ${ }^{\mathrm{H} 277 \mathrm{~N}}$ shRR were generated by PCR mutagenesis using primers $5^{\prime}$-TTCTCCAATGATATCTATAGTACGTATCACTTG TTCCCTCC- $3^{\prime}$ and $5^{\prime}$-TGCTGTAGATATCGTTTGAAAATTGTA ATTGGAGCTCAGGG-3' to alter the shRNA target sequence in pTK-IREShyg-Flag-DcpS ${ }^{\mathrm{WT}}$ and pTK-IREShyg-Flag-DcpS ${ }^{\mathrm{H} 277 \mathrm{~N}}$.

\section{Cell culture, transfections, and lentiviral infection}

SH-SY5Y cells were grown in F/12 (Invitrogen) medium supplemented with $10 \%$ fetal bovine serum, penicillin-streptomycin and sodium pyruvate under $5 \% \mathrm{CO}_{2}$ at $37^{\circ} \mathrm{C}$. HEK293T cells were grown in DMEM (Invitrogen) medium with the same complement of sup- plements as SH-SY5Y cells. RG3039 was administered to the culture medium at a final concentration of $100 \mathrm{nM}$ and cells grown for $2 \mathrm{~d}$ before harvesting. HEK293T cells stably transformed with DcpS specific shRNA (DcpS ${ }^{\mathrm{KD}}$ ) was described in Shen et al. (2008). DcpS ${ }^{\mathrm{KD}}$ cells stably expressing an shRNA-resistant wild type (pTK-Flag$\mathrm{DcpS}^{\mathrm{WT}}$ shRR), catalytically inactive histidine 277 to asparagine mutant (pTK-Flag-DcpS ${ }^{\mathrm{H} 277 \mathrm{~N}}$ shRR) or the empty pTK-Flag vector were generated by transfecting the respective plasmids into $\mathrm{DcpS}^{\mathrm{KD}}$ cells and grown under $3 \mu \mathrm{g} / \mathrm{mL}$ puromycin and $50 \mu \mathrm{g} / \mathrm{mL}$ hygromycin selection $48 \mathrm{~h}$ post-transfection.

All shRNA plasmids and packaging plasmids were purchased from Sigma. HEK293T cells were transfected by pLKO.1-shXRN1 (Sigma \#TRCN0000049676) or pLKO.1-shRRp41 (Sigma \#TRCN0000051365), and pCMV-VSVG and psPAX2 with Lipofectamin2000 (Life Technologies) to generate viral particles. Culture medium was harvested two days post-transfection and frozen at $-80^{\circ} \mathrm{C}$ for storage (Bail et al. 2010).

\section{RNA isolation, reverse transcription, and real-time qRT-PCR}

Cells were treated with actinomycin D (5 mg/L, Sigma) 48 h postRG3039 treatment/lentiviral infection, cells harvested and total RNA isolation carried out with TRIzol (Invitrogen) at the indicated time intervals. Total RNA was treated with DNase (Promega) to degrade DNA prior to oligo(dT) (IDT)-directed reverse transcription with M-MLV-RT (Promega) according to the manufacturer's instructions. Values were quantified by quantitative PCR using SYBR green PCR core reagent (Applied Biosystems) and the abundance of specific mRNAs were quantified using the standard-curve method according to the recommendations of the manufacturer. mRNA levels were normalized to the GAPDH mRNA and plotted against time. PCR primers used are listed in Supplemental Table S2. mRNA half-lives were calculated as in Tan et al. (2014).

\section{Microarray}

SH-SY5Y cells were treated for 48 h with $100 \mathrm{nM}$ RG3039, total RNA isolated with TRIzol (Invitrogen) according to the manufacturer and used for microarray analysis using the Affymetrix U133 Plus 2.0 human microarray at Expression Analysis.

\section{Western blotting}

Cells were sonicated in phosphate-buffered saline, and protein extract was resolved by $12.5 \%$ SDS-PAGE. Affinity-purified DcpS polyclonal antibody (1:200 dilution) (Shen et al. 2008) and monoclonal anti-GAPDH antibody (1:1000 dilution, Santa Cruz) were used for Western blot analysis and visualized using secondary antibodies coupled to horseradish peroxidase (Jackson ImmunoResearch) and chemiluminescence (ECL; GE Healthcare).

\section{5' RACE and DNA gel electrophoresis}

5'RACE was conducted using 5'RACE System for Rapid Amplification of cDNA Ends, version 2.0 (Life Technologies). Primers used in PCR are listed in Supplemental Table S2. PCR products were resolved by $2 \%$ agarose gel electrophoresis and DNA fragments 
purified using QIAquick Gel Extraction Kit (Qiagen) and cloned into pGEM-T Easy Vector (Promega). Four colonies from each of the isoforms were picked and sequenced.

\section{SUPPLEMENTAL MATERIAL}

Supplemental material is available for this article.

\section{ACKNOWLEDGMENTS}

We thank Xinfu Jiao, Madel Durens, You Li, and members of the Kiledjian laboratory for providing constructs and/or helpful discussions throughout this work. This work was supported in part by funding from Cure SMA, Repligen Corporation, and National Institutes of Health (NIH) grant GM067005 to M.K.

Received February 26, 2015; accepted April 9, 2015.

\section{REFERENCES}

Ahmed I, Buchert R, Zhou M, Jiao X, Mittal K, Sheikh TI, Scheller U, Vasli N, Rafiq MA, Brohi MQ, et al. 2015. Mutations in DCPS and $E D C 3$ in autosomal recessive intellectual disability indicate a crucial role for mRNA decapping in neurodevelopment. Hum Mol Genet doi: $10.1093 / \mathrm{hmg} / \mathrm{ddv} 069$.

Anderson JSJ, Parker RP. 1998. The 3' to 5' degradation of yeast mRNAs is a general mechanism for mRNA turnover that requires the SKI2 DEVH box protein and $3^{\prime}$ to $5^{\prime}$ exonucleases of the exosome complex. EMBO J 17: 1497-1506.

Bail S, Kiledjian M. 2008. DcpS, a general modulator of cap-binding protein-dependent processes? RNA Biol 5: 216-219.

Bail S, Swerdel M, Liu H, Jiao X, Goff LA, Hart RP, Kiledjian M. 2010. Differential regulation of microRNA stability. RNA 16: 1032-1039.

Bosse GD, Ruegger S, Ow MC, Vasquez-Rifo A, Rondeau EL, Ambros VR, Grosshans H, Simard MJ. 2013. The decapping scavenger enzyme DCS-1 controls microRNA levels in Caenorhabditis elegans. Mol Cell 50: 281-287.

Butchbach ME, Singh J, Thorsteinsdottir M, Saieva L, Slominski E, Thurmond J, Andresson T, Zhang J, Edwards JD, Simard LR, et al. 2010. Effects of 2,4-diaminoquinazoline derivatives on SMN expression and phenotype in a mouse model for spinal muscular atrophy. Hum Mol Genet 19: 454-467.

Chernyakov I, Whipple JM, Kotelawala L, Grayhack EJ, Phizicky EM. 2008. Degradation of several hypomodified mature tRNA species in Saccharomyces cerevisiae is mediated by Met22 and the $5^{\prime}-3^{\prime}$ exonucleases Rat1 and Xrn1. Genes Dev 22: 1369-1380.

Conti E, Izaurralde E. 2005. Nonsense-mediated mRNA decay: molecular insights and mechanistic variations across species. Curr Opin Cell Biol 17: 316-325.

Gogliotti RG, Cardona H, Singh J, Bail S, Emery C, Kuntz N, Jorgensen M, Durens M, Xia B, Barlow C, et al. 2013. The DcpS inhibitor RG3039 improves survival, function and motor unit pathologies in two SMA mouse models. Hum Mol Genet 22: 4084-4101.

Gu M, Fabrega C, Liu SW, Liu H, Kiledjian M, Lima CD. 2004. Insights into the structure, mechanism, and regulation of scavenger mRNA decapping activity. Mol Cell 14: 67-80.

Hsu CL, Stevens A. 1993. Yeast cells lacking $5^{\prime} \rightarrow 3^{\prime}$ exoribonuclease 1 contain mRNA species that are poly(A) deficient and partially lack the 5' cap structure. Mol Cell Biol 13: 4826-4835.

Jarecki J, Chen X, Bernardino A, Coovert DD, Whitney M, Burghes A, Stack J, Pollok BA. 2005. Diverse small-molecule modulators of SMN expression found by high-throughput compound screening: early leads towards a therapeutic for spinal muscular atrophy. Hum Mol Genet 14: 2003-2018.
Lima CD, Klein MG, Hendrickson WA. 1997. Structure-based analysis of catalysis and substrate definition in the HIT protein family. Science 278: 286-290.

Liu H, Kiledjian M. 2005. Scavenger decapping activity facilitates $5^{\prime}$ to $3^{\prime}$ mRNA decay. Mol Cell Biol 25: 9764-9772.

Liu H, Rodgers ND, Jiao X, Kiledjian M. 2002. The scavenger mRNA decapping enzyme DcpS is a member of the HIT family of pyrophosphatases. EMBO J 21: 4699-4708.

Liu Q, Greimann JC, Lima CD. 2006. Reconstitution, activities, and structure of the eukaryotic RNA exosome. Cell 127: 1223-1237.

Liu SW, Rajagopal V, Patel SS, Kiledjian M. 2008. Mechanistic and kinetic analysis of the DcpS scavenger decapping enzyme. J Biol Chem 283: 16427-16436.

Lykke-Andersen J. 2002. Identification of a human decapping complex associated with hUpf proteins in nonsense-mediated decay. Mol Cell Biol 22: 8114-8121.

Muhlrad D, Decker CJ, Parker R. 1995. Turnover mechanisms of the stable yeast PGK1 mRNA. Mol Cell Biol 15: 2145-2156.

Ng CK, Shboul M, Taverniti V, Bonnard C, Ascia E, Nelson SF, AlRaqad M, Altawalbeh S, Séraphin B, Reversade B. 2015. Loss of the scavenger mRNA decapping enzyme DCPS causes syndromic intellectual disability with neuromuscular defects. Hum Mol Genet doi: 10.1093/hmg/ddv067.

Shalem O, Sanjana NE, Hartenian E, Shi X, Scott DA, Mikkelsen TS, Heckl D, Ebert BL, Root DE, Doench JG, et al. 2014. Genome-scale CRISPR-Cas9 knockout screening in human cells. Science 343: 84-87.

Shen V, Liu H, Liu SW, Jiao X, Kiledjian M. 2008. DcpS scavenger decapping enzyme can modulate pre-mRNA splicing. RNA 14: 1132-1142.

Shukla S, Parker R. 2014. Quality control of assembly-defective U1 snRNAs by decapping and $5^{\prime}$-to-3' exonucleolytic digestion. Proc Natl Acad Sci 111: E3277-3286.

Singh J, Salcius M, Liu SW, Staker BL, Mishra R, Thurmond J, Michaud G, Mattoon DR, Printen J, Christensen J, et al. 2008. DcpS as a therapeutic target for spinal muscular atrophy. ACS Chem Biol 3: 711-722.

Sinturel F, Brechemier-Baey D, Kiledjian M, Condon C, Benard L. 2012. Activation of $5^{\prime}-3^{\prime}$ exoribonuclease Xrn1 by cofactor Dcs1 is essential for mitochondrial function in yeast. Proc Natl Acad Sci 109: 8264-8269.

Song MG, Li Y, Kiledjian M. 2010. Multiple mRNA decapping enzymes in mammalian cells. Mol Cell 40: 423-432.

Tan D, Zhou M, Kiledjian M, Tong L. 2014. The ROQ domain of Roquin recognizes mRNA constitutive-decay element and doublestranded RNA. Nat Struct Mol Biol 21: 679-685.

Taverniti V, Séraphin B. 2014. Elimination of cap structures generated by mRNA decay involves the new scavenger mRNA decapping enzyme Aph1/FHIT together with DcpS. Nucleic Acids Res 43: 482-492.

Thurmond J, Butchbach ME, Palomo M, Pease B, Rao M, Bedell L, Keyvan M, Pai G, Mishra R, Haraldsson M, et al. 2008. Synthesis and biological evaluation of novel 2,4-diaminoquinazoline derivatives as SMN2 promoter activators for the potential treatment of spinal muscular atrophy. J Med Chem 51: 449-469.

van Dijk E, Cougot N, Meyer S, Babajko S, Wahle E, Seraphin B. 2002. Human Dcp2: a catalytically active mRNA decapping enzyme located in specific cytoplasmic structures. EMBO J 21: 6915-6924.

van Dijk EL, Chen CL, d'Aubenton-Carafa Y, Gourvennec S, Kwapisz M, Roche V, Bertrand C, Silvain M, Legoix-Ne P, Loeillet S, et al. 2011. XUTs are a class of Xrn1-sensitive antisense regulatory non-coding RNA in yeast. Nature 475: 114-117.

Van Meerbeke JP, Gibbs RM, Plasterer HL, Miao W, Feng Z, Lin MY, Rucki AA, Wee CD, Xia B, Sharma S, et al. 2013. The DcpS inhibitor RG3039 improves motor function in SMA mice. Hum Mol Genet 22: 4074-4083.

Wang Z, Kiledjian M. 2001. Functional link between the mammalian exosome and mRNA decapping. Cell 107: 751-762.

Wang Z, Jiao X, Carr-Schmid A, Kiledjian M. 2002. The hDcp2 protein is a mammalian mRNA decapping enzyme. Proc Natl Acad Sci 99: 12663-12668. 

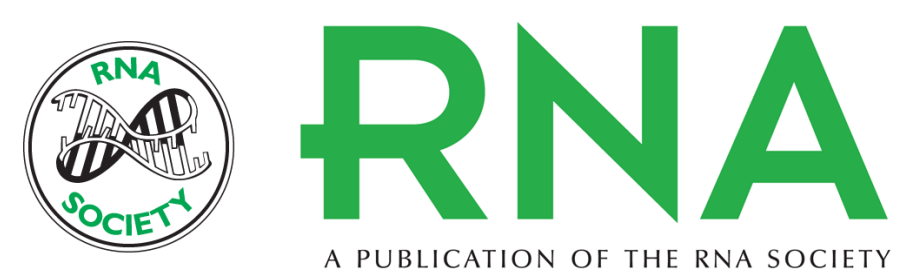

A PUBLICATION OF THE RNA SOCIETY

\section{DcpS is a transcript-specific modulator of RNA in mammalian cells}

Mi Zhou, Sophie Bail, Heather L. Plasterer, et al.

RNA 2015 21: 1306-1312 originally published online May 22, 2015

Access the most recent version at doi:10.1261/rna.051573.115

Supplemental Material

References

Creative Commons License

Email Alerting Service
http://rnajournal.cshlp.org/content/suppl/2015/05/06/rna.051573.115.DC1

This article cites 34 articles, 16 of which can be accessed free at: http://rnajournal.cshlp.org/content/21/7/1306.full.html\#ref-list-1

This article is distributed exclusively by the RNA Society for the first 12 months after the full-issue publication date (see http://rnajournal.cshlp.org/site/misc/terms.xhtml). After 12 months, it is available under a Creative Commons License (Attribution-NonCommercial 4.0 International), as described at http://creativecommons.org/licenses/by-nc/4.0/.

Receive free email alerts when new articles cite this article - sign up in the box at the top right corner of the article or click here. 